\title{
REVIEW
}

\section{CAN ANYBODY HEAR ME? A CRITICAL ANALYSIS OF YOUNG RESIDENTS’ VOICES IN TOURISM STUDIES}

\author{
ANTONIA CANOSA,* BRENT D. MOYLE,† AND MEREDITH WRAY \\ *Centre for Children and Young People, Southern Cross University, \\ Lismore, New South Wales, Australia \\ †Griffith Institute for Tourism, Griffith University, Gold Coast, Queensland, Australia \\ $\ddagger$ Wray Sustainable Tourism Research and Planning, Myocum, New South Wales, Australia
}

\begin{abstract}
In this review article, tourism is recognized as a powerful force of change for host communities. The authors maintain that many empirical studies of residents' perceptions of tourism have argued that tourism has the ability to transform the lives of locals who inhabit a given destination region, generating both positive and negative economic, environmental, and sociocultural impacts there. However, the authors suggest that the focus of these received studies has been placed on the perceptions and experiences of adult residents, resulting in an absence of research that examines how young residents view, perceive, and adapt to tourism in their communities. To address this gap, this review article critically analyzes the role of young residents in Tourism Studies to date. An inventory of 30 previous studies that focused on young residents in tourism research was compiled and analyzed. Adapting a framework of the presence and role of Indigenous people in tourism research, the authors classified these articles into three categories-namely, the silent, the acknowledged, and the youth-focused. In this inspection, key findings identified the lack of children's and young people's agency and voice, providing a theoretically driven undercurrent guiding future inquiry and developing a pathway toward new "voice-generative" methods. The authors recommend that the specific approaches that they identify for deployment in the field should be ethically sensitive to the needs of children and young people and thereby be more accommodating in their capacity to develop and enhance discourse on youth in tourism. (Abstract by Reviews Editor)
\end{abstract}

Key words: Children; Young people; Youth; Participation; Collaboration; Agency; Voice; Critical tourism studies 


\section{Introduction}

Tourism, as a subject of investigation, has evolved in different stages and can be grouped into positions or platforms (Jafari, 2003). Within this body of research, Jafari (2003) proposed that the "advocacy platform" was the first stage when literature began to emerge focused primarily on the economic benefits of tourism, such as employment opportunities, foreign exchange, development of infrastructure, and the multiplier effect. During the late 1970s, several social scientists, and primarily anthropologists, began to critically analyze the negative effects or "dark side" of tourism (Easterling, 2004, p. 45). Jafari labeled this stage the "cautionary platform” because a counterargument to tourism's economic benefits started to rise among those concerned about the impacts of tourism on host communities.

Since these seminal studies, a great deal of research has been conducted on residents' perceptions of the social impacts of tourism (Deery, Jago, \& Fredline, 2012). Sharpley (2014) noted that the field of tourism social impact studies has been "one of the most researched topics within Tourism Studies” (p. 46). Despite its growing popularity, research in this space has been critiqued for providing a narrow and simplistic view of tourism as an external agent affecting otherwise pristine life ways (Hollinshead, 2009; Lanfant, Allcock, \& Bruner, 1995; Leite \& Graburn, 2009; Wood, 1980). In addition, Hollinshead (2009) argued that these studies envision host communities as mere passive agents of the tourism phenomenon, whereas in reality host communities often respond and adapt to change in creative ways.

In response to such criticisms, recent reviews of the body of knowledge of the social impacts of tourism have heralded the need for a new research agenda (Deery et al., 2012; Sharpley, 2014). Sharpley (2014) argued that we need to understand the adaptations and transformations that occur at a local level and to heed to the voices of local residents. Furthermore, Nunkoo, Smith, and Ramkissoon (2013) have encouraged researchers to embrace more interpretive and triangular approaches that allow for the historical and sociocultural contexts in which residents' attitudes and perceptions are formed to transpire.
The aim of this review article is to contribute to the evolution of tourism research by exploring and critically evaluating the role of children and young people in host communities. To achieve this objective, the study adapts a framework developed by Nielsen and Wilson (2012) that examined the presence and role of Indigenous people in tourism research. The framework used a spectrum involving four typologies ranging from invisible (referring to research that was produced and presented without involving Indigenous people) to identified, stakeholder, and Indigenous-driven. The last typology on this spectrum includes tourism research driven by Indigenous people, including high levels of collaboration, which often results in coauthorship of manuscripts. This approach was deemed appropriate for this study, given that arguably young residents and Indigenous people are vulnerable and underrepresented groups within the community, further marginalized by being considered as the "objects" rather than the "subjects" of investigation in Tourism Studies (Freire, 1970/2000). An inventory of previous studies focused on young residents in tourism research was then compiled and analyzed using this typology.

The term "young people" in this review article is often used interchangeably with the term "child." The United Nations' Convention on the Rights of the Child defined "child" as all those under the age of 18 years, "unless under the law applicable to the child, majority is attained earlier" (Morrow, 2011, p. 2). The definition acknowledges the social construction and cultural relativity of the term "childhood," which may differ according to the particular context, culture, or environment (Morrow, 2011). This cultural relativity is evidenced by the way "young people" are conceptualized in the studies presented in this review article. In some studies, "youth" or "young” refers to residents more than 18 years of age (between 18 and 30 years of age), whereas in other studies, these terms refer to individuals less than 18 years of age (with 18 years of age seen by these researchers as a clear threshold into adulthood).

A key contribution of this article in Tourism Analysis is to demonstrate and raise awareness concerning the lack of young people's voice, engagement, and participation in tourism research and, specifically, within host communities. Moreover, 
this review article demonstrates how the positivist legacy in tourism social impact studies has precluded the involvement, and has excluded the voices, of young residents less than 18 years of age. This article thereby contributes to the developing work of critical tourism theorists by highlighting the importance of including the voices of the marginalized and unrecognized agents in Tourism Studies and by advocating for research that is emancipatory and that brings about positive change among the people we study (Bramwell \& Lane, 2014; Higgins-Desbiolles \& Whyte, 2013; Pritchard, Morgan, \& Ateljevic, 2011). An overview of community research in tourism studies is provided followed by a critical review of young residents' presence, role, and voice in tourism research.

\section{Community Research in Tourism Studies}

Community research in Tourism Studies emerged during the late 1970s, when several social scientists, including anthropologists, started to explore the negative outcomes of tourism for host communities (Easterling, 2004). The seminar held by the World Bank and the United Nations Educational, Scientific and Cultural Organization (UNESCO) in 1976 on "The Social and Cultural Impacts of Tourism" marked the beginning of tourism research focused on host communities (Moyle, Weiler, \& Croy, 2013). These early critical accounts assumed that tourist destinations were passive recipients subject to the exogenous forces produced by tourism (Leite \& Graburn, 2009).

The influences of structural Marxism and later the concept of political economy in the social sciences may have been the cause for this blind assumption that human action and historical processes were "almost entirely structurally or systemically determined” (Ortner, 1984, p. 144). These views are fairly representative of early tourism research on communities and provided the starting point for further studies that now form part of a body of knowledge referred to as "tourism social impact studies."

Tourism research on social impacts has mainly focused on residents' perceptions as a basis for understanding attitudes and ultimately community support for tourism development (Moyle, Croy, \& Weiler, 2010a). Typically, such studies segmented residents using a raft of sociodemographic variables in an effort to predict support for tourism (Haralambopoulos \& Pizam, 1996). Mounting empirical work soon led to the identification of social exchange theory as a theoretical framework that was well positioned to provide conceptual clarification on the interaction between hosts and guests (Moyle, Croy, \& Weiler, 2010b).

Despite this growing body of knowledge, Sharpley (2014) has recently questioned whether the volume of research has resulted in actual progress and in a holistic understanding of residents' concerns about tourism development. Likewise, Deery et al. (2012, p. 72) have pointed to the need for a new research agenda that includes qualitative and interpretive approaches to fully understand residents' experiences and reactions to tourism. According to Hollinshead (2009, p. 146), we must overcome the common cliché that tourism is an "uninvited" and "sterile cultural force" that comes from the outside to affect original and distinct local communities.

Communities respond to change and international tourism in transformative ways, which often results in tourism becoming intricately intertwined with local culture. Wood (1980, p. 565) argued that we should abandon "Western romantic ideals of cultural preservation" and acknowledge that cultures are not passive but in constant flux and renewal. In his view, efforts should be made to understand the "cultural strategies that people develop to limit, channel, and incorporate the effects of international tourism” (Wood, 1980, p. 566).

Community-focused tourism research has reached a level of maturity displayed by the theoretical and methodological eclecticism of studies in this area and the varying disciplinary influences. Nevertheless the "voices" of marginal members of host communities such as children and young people remain unheard in Tourism Studies. This absence is a particularly pressing issue that is evidenced by the review of the following literature.

\section{Young People Within Tourism Studies}

Children and young people have been an "underresearched" and "undervalued" field of enquiry in Tourism Studies (Thornton, Shaw, \& Williams, 1997, p. 287). Almost 20 years after this initial statement, recent studies are still acknowledging the absence of children in the tourism literature (Poria 
\& Timothy, 2014; Small, 2008). Notable exceptions include recent studies on the role of children and young people in family travel decision making (e.g., Schänzel, Yeoman, \& Backer, 2012) as well as studies on children's and young people's experiences and memories of family holidays (e.g., Small, 2008).

In the 1980s, Graburn (1983) commented that the impacts of touring should be examined at different stages in the life cycle of the individual. Graburn argued that this would be important in understanding the formation of "identity and aspirations" and the development of "attitudes towards other people and places in the world" particularly among children and young people (p. 2). Since this time, there have been a multitude of studies on young travelers. These studies have focused on the educational values of traveling, particularly with the development in recent years of socially responsible tourism such as volunteer and pro-poor tourism (e.g., Bailey \& Russell, 2010). Other studies have focused on young travelers' motivations and behaviors (e.g., Boukas, 2013).

Although research on youth and tourism is beginning to gain traction among scholars, most of these studies do not rely on data generated directly from children (Poria \& Timothy, 2014). In addition, previous studies to date have focused primarily on children and youth as guests (tourists) rather than hosts, meaning little attention has been given to children and young people as residents of host communities. The insights provided by Graburn (1983), although focused on tourists, can potentially be applied to understand how growing up in a host community affects children and young people at a critical stage of their lives.

Furthermore, previous research has suggested young hosts are more susceptible to the demonstration effects of tourism (Leiper, 2004; Mathieson \& Wall, 1982). However, this belief still remains empirically barren, with limited primary data from young residents of host communities (Canosa, Brown, \& Bassan, 2001; Crick, 1989; Gamradt, 1995). We know little about the coping skills and resilience of children and young people to tourism, suggesting literature in this area requires further expansion in tourism studies.

\section{Methodological Approach}

The purpose of this review article is to identify the presence, role, and voice of young residents in
Tourism Studies from a critical and interpretative ontology. To achieve this objective, we undertook a search of google scholar for previous studies that contained a combination of the key words "young people," "youth," and "child” with "tourism.” The search was limited to tourism and anthropological literature, in which most studies on young people as hosts are published. Studies on youth or children as tourists were excluded from the database, with only studies that explicitly mentioned young people as residents of tourist destinations included. A total of 30 studies were analyzed and grouped into one of the three categories adapted from Nielsen and Wilson (2012): silent, acknowledged, or youth-focused.

Poststructural discourse analysis was then used to analyze the written text (including theoretical approach and choice of methodology) as an expression of the authors' ideas, ideologies, and attitudes in relation to the production of knowledge (Wetherall, Taylor, \& Yates, 2001). The analysis sought to examine why some discourses, mainly from adult respondents, were generally taken as truths, whereas other ways of thinking/being/ doing (children's and young people's views) were marginalized in findings. The common discourse being, until recently, that children and young people are immature, and their views and opinions are thus unreliable (Prout \& James, 1997). From this, the studies were classified according to the extent to which they represent the marginalization of youth in the research process.

The silent category includes studies in which the focus is on other issues, and children and young people are only briefly mentioned, and their voices are not included. The acknowledged position includes research in which children and young people are identified as a cohort within the host community and included in samples, but their involvement and voices still remain absent. Finally, the youth-focused phase includes studies in which children and young people are the main focus of the research and their voices are often (but not always) included in research findings.

We acknowledge, however, that the way studies have been classified in this article is contingent to our epistemological and ontological standpoint, and we are careful not to make claims to objectivity because, in a poststructural/Foucauldian sense, there are no universal truths but only interpretations 
of the material under review (Humes \& Bryce, 2003). A summary of the academic literature according to the three typologies is provided in Table 1, which is, however, by no means comprehensive and/or exhaustive; selected studies are only used as examples to best describe each position.

\section{The Silent Phase}

The silent position refers to studies that make reference to young people, but their voices are not included, and they are not involved in the research process. As shown in Table 1, this category primarily includes early anthropological studies in developing nations and tourism desktop and review research. Studies that were first presented at the 1976 conference on "The Social and Cultural Impacts of Tourism” organized by the World Bank and UNESCO and that were later collected in V. L. Smith's (1977) seminal book Hosts and Guests: The Anthropology of Tourism are included in this position. These early accounts often discussed the negative impacts of tourism on host communities and the demonstration effects that tourism had on youth.

V. L. Smith (1977), in her study of Eskimo tourism, and Swain (1977), in her account of the Kuna women of Panama, both referred to young members of the community choosing education and formal employment in tourism as an attempt to achieve Western aspirations. Similarly, Boissevain's (1979) ethnographic study of Maltese culture revealed that young residents were more inclined to emulate tourists' behaviors, particularly the sexual freedom demonstrated by young foreigners. On the contrary, Cohen's (1982) study found that tourists' behaviors (e.g., drug use, naked bathing) infringed on local customs and offended local residents, particularly young people and women in the host community. This resentment often translated into hostility and crime toward tourists.

These early studies stressed the modernizing and imperialistic-like forces of tourism on host communities and the subsequent acculturation of young residents (Nash, 1989). A common issue raised in these seminal works was the demonstration effect of modern Western ways of life, leisure, and consumption on young Indigenous populations. Leiper (2004, p. 238) defined the demonstration effects of tourism as the display of "foreign cultures, behaviors, attitudes and what is often termed lifestyles" that occur in front of locals. Leiper further argued that young hosts are particularly susceptible and

Table 1

A Critical Typology of Young Residents’ Voices in Tourism Research

\begin{tabular}{|c|c|c|c|}
\hline Position & Role of Young Residents & Research Focus & Select Examples \\
\hline Silent & $\begin{array}{l}\text { Young people are referred to, and } \\
\text { often the negative impacts of tourism } \\
\text { on their lives are highlighted. Young } \\
\text { people remain invisible, and their } \\
\text { voices are not included. }\end{array}$ & $\begin{array}{l}\text { Early anthropological } \\
\text { fieldwork in developing } \\
\text { countries; tourism } \\
\text { desktop/review research }\end{array}$ & $\begin{array}{l}\text { V. L. Smith (1977), Swain (1977), } \\
\text { Boissevain (1979), Cohen (1982), } \\
\text { Mathieson and Wall (1982), Murphy } \\
\text { (1985), Leiper (2004), Witt (1991) }\end{array}$ \\
\hline Acknowledged & $\begin{array}{l}\text { Young people are identified, but } \\
\text { age is only used as a demographic } \\
\text { predictor of attitudes and perceptions } \\
\text { toward tourism. Young people's } \\
\text { involvement and voice are still not } \\
\text { present. Most studies refer to young } \\
\text { people as } 18 \text { years of age and older. }\end{array}$ & $\begin{array}{l}\text { Social impacts of tourism } \\
\text { studies; studies on } \\
\text { residents' attitudes and } \\
\text { perceptions toward } \\
\text { tourism }\end{array}$ & $\begin{array}{l}\text { Haralambopoulos and Pizam (1996), } \\
\text { Brunt and Courtney (1999), Chen } \\
\text { (2000), Gu and Ryan (2008), Huh and } \\
\text { Vogt (2008), Tovar and Lockwood } \\
\text { (2008), Nunkoo and Ramkissoon } \\
\text { (2010), Long and Kayat (2011) }\end{array}$ \\
\hline Youth-focused & $\begin{array}{l}\text { Young people are the focus of } \\
\text { the study, and their voices are } \\
\text { sometimes included; however, their } \\
\text { involvement is still limited. Most } \\
\text { of these studies also refer to young } \\
\text { people as } 18 \text { years of age and older. }\end{array}$ & $\begin{array}{l}\text { Young people's attitudes } \\
\text { and perceptions toward } \\
\text { tourism; identity, } \\
\text { place, and belonging; } \\
\text { citizenship rights and } \\
\text { sustainable livelihoods }\end{array}$ & $\begin{array}{l}\text { Crick (1989), Brown (1992), Gamradt } \\
\text { (1995), Dahles and Bras (1999), } \\
\text { Canosa et al. (2001), Gössling } \\
\text { et al. (2004), Huberman (2005), } \\
\text { Andreassen (2008), Faccioli (2011), } \\
\text { Buzinde and Manuel-Navarrete } \\
\text { (2013), Anglin (2015), Canosa (2014) }\end{array}$ \\
\hline
\end{tabular}

Note. Adapted from Nielsen and Wilson (2012). 
easily influenced by foreign lifestyles and cultures. In Cyprus, Witt (1991) reported on the vulnerability of young hosts to the potential social impacts of the demonstration effects of tourism.

These early anthropological accounts were followed by first reviews of the sociocultural impacts of tourism on host communities (Mathieson \& Wall, 1982; Murphy, 1985). Mathieson and Wall (1982) and Murphy (1985) argued that young people of traditionally closed societies observed the freedom and material superiority of young traveling Westerners seeking to emulate their lifestyle. As such, research in the silent phase is largely conceptual in nature, with the majority of interpretations and conclusions drawn from Western and Eurocentric observations without hearing directly from young people. Moreover, no effort is made to explore issues concerning tourism development from a child perspective. Their voice and involvement in the research thus remain undoubtedly absent.

\section{The Acknowledged Phase}

This category refers to studies that have identified young people as a cohort or subgroup of the population. Nevertheless, age is only used as a demographic predictor of attitudes and perceptions toward tourism. The acknowledged position mainly includes empirical and quantitative studies on residents' perceptions of tourism impacts, and although young residents (mainly 18 years of age and older) are identified, their voice and involvement still remain absent.

Haralambopoulos and Pizam's (1996) study on the Island of Samos in Greece revealed that the increase in job opportunities in the tourism and hospitality industry resulted in a substantial decrease of youth's out-migration from the island. This, in turn, resulted in residents having positive perceptions of tourism development. On the contrary, Brunt and Courtney's (1999) study on host perceptions of the sociocultural impacts of tourism in Dawlish (UK) revealed that young, educated people who were not satisfied with the limited employment prospects offered by the tourism industry were choosing to move away.

Studies by Gu and Ryan (2008) in China and Huh and Vogt (2008) in Alaska also found that sociodemographic characteristics significantly influenced residents' perceptions of tourism impacts and their support for tourism development. In these studies, younger residents were more favorably disposed to tourism and supported further tourism development. According to $\mathrm{Gu}$ and Ryan, "younger people, being more used to a world of change, may be more tolerant of tourism and its impacts, while those who have been long-term residents might not be” (p. 643).

On the contrary, Chen's (2000) study in Alaska and Tovar and Lockwood's (2008) study in Tasmania (Australia) revealed that young people were more aware and concerned about the effects of tourism on the community's quality of life. This was due to a perceived increase in the prices of goods, services, and rent. Similarly, Nunkoo and Ramkissoon's (2010) study also found that younger residents on the Island of Mauritius were more concerned about the environmental damage of tourism than older residents.

In this phase, referred to by Jafari (2003) as the "knowledge-base" platform, tourism researchers sought to operationalize and measure residents' perceptions of tourism. There is, however, a complete lack of children and young people less than 18 years of age in research samples. The quantitative approach is also not conducive to the emergence of participants' voices, and young people are not actively involved in the research process.

\section{The Youth-Focused Phase}

Research in the youth-focused position deliberately focuses on the views, perceptions, and experiences of young residents in tourism research. Young residents are the primary focus of these studies, and their voices are often (but not always) included and presented in the findings. Studies in this position range from anthropological studies to tourism impact studies, and the methods used are either purely qualitative such as ethnographic methods or mixed. An early example of the youth-focused phase is Crick's (1989) ethnographic study in Sri Lanka. Crick explored how school-age children growing up in a tourist destination in Sri Lanka perceived the "hippie tourist," providing an insight into the way tourism was influencing young residents' lives. Common problems included young people dropping out of school and engaging in activities such as prostitution and drug dealing. In an effort to 
make the views and voices of the school-age population more prominent, the author included lengthy quotations that were collected through an essay writing exercise.

Following Crick's (1989) study, Brown (1992) in Gambia and Dahles and Bras (1999) in Indonesia both reported on the demonstration effect that Western tourists had on young residents. These authors focused specifically on young male residents exploring their role as "culture brokers" and catalysts for social change in the host community. Young residents working in the informal tourism sector as guides or escorts often deliberately sought romance and entered into sexual relationships with Western female tourists with the intent to improve their financial situation (Dahles \& Bras, 1999).

Likewise, Gamradt (1995) in Jamaica and Canosa et al. (2001) in Italy both explored the developmental/socialization process of young people living in tourist destinations. Using more child-centered research tools (drawings and open-ended questions), Gamradt's study focused on school children's views and perceptions of tourists in Jamaica, revealing that of the six schools examined, respondents from the schools closer to touristic activities produced more detailed and imaginative drawings of visitors. This time in a developed, European country, Canosa et al.'s study found that older adolescents (16-19 years), although more aware of the negative implications of tourism, were more capable of managing the complex social relations with tourists and adapting to the changes at the beginning of each tourist season compared with the younger adolescents (13-15 years) living in an Italian coastal town (Positano). According to these authors, children and young people may experience a significantly different and unique developmental/ socialization process when growing up in communities where tourism is the main economy.

Although these early studies in the youthfocused typology have focused specifically on youth growing up in host communities, their voice and involvement in the research process are still limited. Recent studies are, however, beginning to delve deeper into the issues faced by young people growing up in tourist destinations. These studies often make use of innovative research methods, such as the life history approach used by Möller (2012) in a study on young residents of an international ski destination in Sweden. The study revealed tourism is important for young residents (20-35 years) both socially and economically.

Likewise, Huberman (2005) used ethnographic methods to explore how tourism has shaped children's lives in Banaras, India. Huberman explored the role of children working in the informal tourism service industry, particularly girls between the ages of 8 and 14 years who sell postcards and trinkets to tourists along the riverfront. Although these youth are viewed by adults in the community as embodying the social ills of modern times (consumerism, Westernization, and loss of traditional values), they are actively contributing to the livelihoods of their families and communities. In contrast, Gössling, Schumacher, Morelle, Berger, and Heck's (2004) study in Madagascar shows that tourists' monetary donations to street children are potentially detrimental to their livelihoods, placing them in danger of sexual exploitation.

Although quantitative in nature, Faccioli (2011) and Wu and Pearce (2013) made use of interesting theoretical approaches. Faccioli used the concept of "participation rights” to prove that young people's (18-35 years) knowledge and participation in the decision making processes of tourism development significantly improved their perceptions of tourism in a mature Alpine destination in Folgaria (Italy). Using the "sustainable livelihood" approach, Wu and Pearce argued that young hosts (18 years of age and older) are able to contribute (and in some instances drive) the tourism development process in two villages in China.

Researchers have also recently engaged with the "geographies of childhood" in a tourism context. Buzinde and Manuel-Navarrete (2013) have made use of child-centered techniques, such as drawing- and writing-based worksheet exercises, to explore how children between 10 and 14 years of age perceive their sociospatial surroundings and the boundaries created by enclave tourism development in two Mexican tourist destinations.

The innovative methods and conceptual frameworks used in these youth-focused studies reveal that children and young people are far from being passive victims of the modernizing impacts of tourism. They are often actively and creatively contributing to community life, and their agency and voice shines bright in the studies discussed in this 
phase. Nevertheless, similarly to the stakeholder position described by Nielsen and Wilson (2012), research in the youth-focused typology still does not give young people ownership and control over the research process, and as a result, there are limited benefits to participants. As such, young residents are still viewed as the objects of investigation rather than collaborators in the research process (Freire, 1970/2000).

Notable exceptions to this trend include studies that take a collaborative approach to actively engage and include young participants in the research process. Through extensive ethnographic fieldwork (Andreassen, 2008), visual ethnography and participatory methods (Canosa, 2014), and photovoice interviews (Anglin, 2015), these studies explore the cultural changes taking place in communities from a child perspective. Canosa (2014) argued that often young respondents are actually keen to participate in the research process and presentation of findings, choosing their own quotes and having an active voice in the narratives. Likewise, Anglin (2015) argued that creative mediums such as photography provide an opportunity for young people to be actively involved in the research, stimulating in-depth and critical discussion among participants.

As evidenced by the studies discussed, a new phase is in its embryonic stages, a phase that will see young people gain increasing agency and control over the research process and presentation of findings. Nevertheless, researchers need to be sensitive to the potential harms and impacts that participating in research may have on children and young people (Graham, Powell, Taylor, Anderson, \& Fitzgerald, 2013) and need to choose methods that will provide opportunities for meaningful educational outcomes and benefits to the young people involved (i.e., participatory and collaborative approaches; Cammorota \& Fine, 2008).

\section{Discussion}

This review article has traced and critically analyzed a range of anthropological and tourism studies in which young residents' presence, role, and voice have been classified as silent, acknowledged, or youth-focused. The article also demonstrates how early studies on host communities in the tourism and anthropology literature have mainly focused on the negative impacts of tourism on young people (e.g., demonstration effects). In the silent phase, youth are sometimes mentioned within the broader context of the host community, but their role remains minimal, and their voices are not included. The main theoretical underpinning of these studies is the "impact model" of tourism (Leite \& Graburn, 2009), and although ethnographic methods are used, most interpretations and conclusions are drawn from Western/Eurocentric observations, and child-centered approaches are seldom used.

The acknowledged stage emerged because of the shift of tourism research into a phase of empirical exploration (knowledge-based platform). During this stage, researchers began measuring residents' attitudes and perceptions toward tourism and its impacts. In this phase of statistical/quantitative investigations, young people are merely referred to as a demographic variable and are compared with other age cohorts within the host community to measure and predict support for future tourism development. The impact model of tourism continues to be the main overarching conceptual framework with some studies, adopting approaches such as community perceptions and attitudes (Brunt \& Courtney, 1999; Haralambopoulos \& Pizam, 1996; Nunkoo \& Ramkissoon, 2010), quality of life (Chen, 2000; Tovar \& Lockwood, 2008), social exchange theory (Long \& Kayat, 2011), and place attachment (Gu \& Ryan, 2008). In the acknowledged phase, there still exists a noticeable lack of children and young people less than 18 years of age in research samples. In addition, those who are included in research samples (18 years of age and older) are silenced by the standardized modes of knowledge production.

Finally, in the youth-focused phase, young people are the primary focus of investigation. Although their voices often (but not always) transpire in research findings, their involvement in the research process still remains limited. Methodological innovation is evident with studies adopting child-centered approaches, such as ethnography, photovoice, drawings, essay writing exercises, and collaborative approaches. Theoretical and conceptual advancement are also noticeable, with studies adopting identity theories (Andreassen, 2008; Anglin, 2015; Canosa, 2014), sense of place and belonging (Canosa, 2014), third space (Andreassen, 
2008), citizenship rights (Faccioli, 2011), and sustainable livelihoods (Wu \& Pearce, 2013).

Nevertheless, as demonstrated in Table 1, there are only three positions identified. The fourth position, which is unfortunately still missing in Tourism Studies, is the youth-driven phase (see Fig. 1). This position would see researchers adopt more participatory research methods to empower young residents of host communities to conduct and engage in research to affect change in their communities. The transformative values put forward by the critical turn in tourism studies (Higgins-Desbiolles \& Whyte, 2013; Pritchard et al., 2011) are conducive to the exploration and adoption of more participatory methods to delve deeper into the issues faced by youth growing up in tourist destinations and, indeed, to "explain" rather than merely “describe” residents' perceptions of tourism (Deery et al., 2012, p. 72).

The positivist legacy, which has until recently dominated Tourism Studies (and, in particular, tourism social impact studies/residents' perceptions), has precluded the involvement of young people in the research process and indeed has often silenced the voices of youth in the community. As Small (2008) argued, "most of the research on age has often been undertaken within a positivist paradigm with the emphasis on description rather than social understanding” (p. 772). If social understanding and positive transformational change among residents and youth of tourist destinations is to be achieved, innovative methods that find their roots in nonpositivist paradigms need to be used. As Westwood (2007) argued, "tourism research should be embracing innovation and progressive approaches . . . actively involving participants in various ways and ... [adopting] exciting, creative and subjective methods and techniques" (p. 313).
Such trends are already evident in other disciplines, such as education and youth studies, in which critical and participatory approaches are increasingly being used (Cammarota \& Fine, 2008). Collaborative forms of research are also advocated by critical/ interpretative (with an inclination toward postdisciplinary) theorists in Tourism Studies, who challenge the existing structures of power and privileges in the research process (Hollinshead, 2010). These collaborative approaches could provide youth with the opportunity to be involved in every phase of the research process, from learning about the implications of tourism development in their communities to data collection, interpreting, and proposing strategies to overcome the numerous and often neglected problems that youth face growing up in a tourist destination. Indeed, it is during such collaborative projects, and with the help of "adult allies," that young people are empowered to critically analyze the forces that shape their world and to bring about positive transformational change in their communities (Kincheloe, McLaren, \& Steinberg, 2011).

Nevertheless, doing research in the youth-focused and youth-driven phases poses considerable challenges for tourism academics that may not be familiar with the complexities of doing research with children. Working with children and young people requires researchers to be "open, reflexive and collaborative in their ethical decision-making” and particularly attuned to the ethical principles of "respect," "benefit," and "justice” (Graham et al., 2013, p. 21). The Ethical Research Involving Children compendium and website created by the Centre for Children and Young People at Southern Cross University (Australia) in collaboration with UNICEF is a particularly helpful guideline containing numerous resources for researchers wanting to
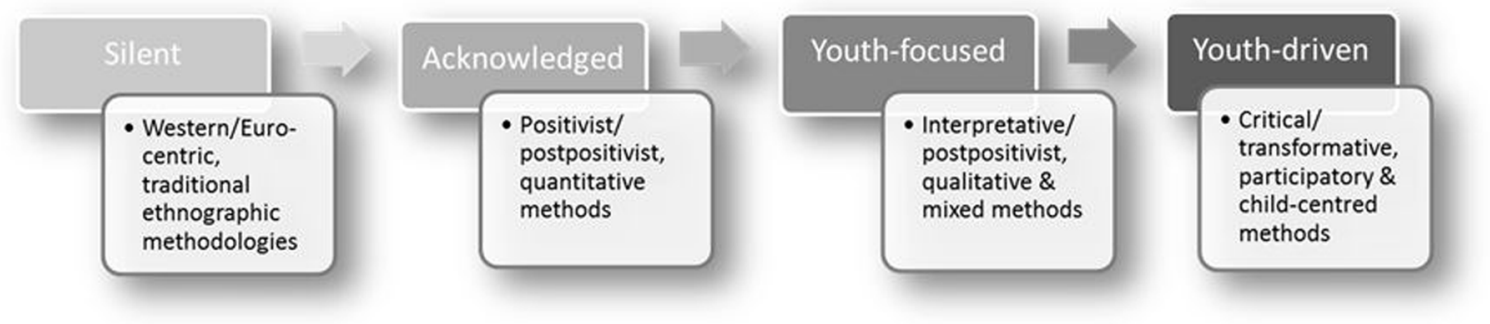

Figure 1. Transition to a youth-driven approach in tourism studies. 
know more about doing research with children and young people.

As the review of the literature revealed, the majority of the received research examined within Tourism Studies has focused on young people 18 years of age and older. Young people and children less than 18 years of age are, in fact, often viewed as immature, so they are often excluded from research samples. Thinking of young adults coming of age at 18 , and their ability to vote or drive as a clear threshold into adulthood, limits our understanding and ability to conduct research on/with youth. Adulthood is a loosely bounded, fluid status that develops a lot earlier in the form of young people's aspirations (Morrow, 2011).

The shift in conceptualizing youth as capable and active agents in our society, which follows and builds on the creation of the United Nations Convention on the Rights of the Child in 1989, needs to be extended to tourism research. Figure 1 shows how the progress in the field of children and young people in community-focused tourism research is slowly moving in this direction, with early studies focusing on tourism as a structural force affecting youth in host communities (silent and acknowledged phases), to a greater focus on identifying the issues and concerns about tourism from a youth or child perspective (youth-focused and youthdriven phases). Obviously, there is still a long way ahead in achieving this fourth youth-driven phase, which will extend children's "rights discourse" to tourism studies.

The rights discourse views children as citizens in the present (and not just as future citizens), capable of making a contribution to their communities (A. B. Smith \& Bjerke, 2009). In the past, the view that children lacked competence and required protection and nurturance has often been used "to deny them agency and limit their citizenship rights” (A. B. Smith \& Bjerke, 2009, p. 18). Today, children and young people are recognized as active citizens with the right to participate and have a say in matters that affect them (Morrow, 2011).

It is precisely the exploration of the agentive and active role of residents (youth and children included) of host communities that should be included in the research agenda for communityfocused tourism research (and, in particular, tourism social impact studies) and that may well provide new and interesting research avenues for a field that Deery et al. (2012) argued is in a "state of arrested development” (p. 65). Critical enquiry and collaborative learning are essential if the many "missing stories of the diverse, minority and marginalized populations" are to be uncovered (Jamal, Taillon, \& Dredge, 2011, p. 145; Wray, 2011).

\section{Conclusion}

The intent of this review article was to critically analyze the presence, role, and voice of young residents in tourism research. The article makes an important contribution to Tourism Studies by highlighting the lack of research specifically focused on children and young people and the need for greater consultation with and involvement of youth in tourism research. The conceptual model presented in Figure 1 shows the evolutionary progress in community-focused tourism research concerned with children and young people and highlights directions for future research. In the initial stages of the silent, acknowledged, and youth-focused phases, there is little opportunity for young people to be actively involved in the research, and their voices remain largely absent from research findings. There is now an opportunity to work toward a youth-driven stage and to extend agency to younger residents of host communities to express their views and opinions about tourism through participatory and collaborative research that will ultimately benefit them and the communities where they live. In addition, childcentered approaches can potentially be used in other areas of Tourism Studies, such as family tourism, volunteer youth tourism, and studies of young travelers' behaviors and consumption patterns.

Prout and James (1997) argued that children are an invisible group in our society and that, until recently, their "silence" has been common in the social sciences. This still holds true in Tourism Studies. Young residents of tourist destinations are underrepresented in tourism research and are indeed a "voiceless population" or "missing host" (Canosa \& Wray, 2013; Wu \& Pearce, 2013). If we are to avoid the "black boxing" of knowledge production, we need to challenge the dominant views of what constitute appropriate research topics by including the voices of marginalized and silent minorities, such as "homosexual voices," "Black and ethnic 
minority groupings” (Tribe, Xiao, \& Chambers, 2012, pp. 29-30), and - to which we would like to add-children and young people.

By critically analyzing tourism research on communities and highlighting the absence of previous research on and with children, this article has sought to contribute to the growing field of Critical Tourism Studies. Nevertheless, mainly tourism and anthropological studies have been included in this analysis. Taking a broader approach to include studies in the crime and law literature as well as the childhood studies literature would reveal a growing body of knowledge in the area of children's rights in relation to their exploitation in human trafficking and sex tourism (e.g., Walters \& Davis, 2011).

In addition, although there seems to be a chronological order to the typologies presented here, each phase is not as distinct as Figure 1 implies, with considerable overlap of studies between the typologies. Although future tourism research on host communities should strive to include young people less than 18 years of age, this poses considerable complexities, including securing formal approval for the project from universities' ethics boards; gaining access to the field and negotiating parental informed consent; and generally respecting and valuing all children affected by the research, not just those directly involved in the process (Graham et al., 2013).

Indeed, if the complexities and problematics of doing research with children and young people are successfully negotiated, new opportunities will arise to uncover a different and seldom recognized angle of vision in Tourism Studies - the world as seen, understood, and experienced by young people. Naturally this has not been a priority in Tourism Studies/Management/Planning precisely because children and young people are not viewed as contributing stakeholders in the business/managerial milieu of tourism. However, with the propagation of a critical scholarship in Tourism Studies, there is now an opportunity to end the silence of marginalized members of the community and to place childcentered research on the agenda.

\section{References}

Andreassen, O. I. R. (2008). When home is the navel of the world: An ethnography of young Rapa Nui between home and away (Unpublished doctoral dissertation). University of New South Wales, Sydney, Australia.
Anglin, A. E. (2015). Voices from Costa Rica: Exploring youth perceptions of tourism and the influence of tourism on identity formation and cultural change. Journal of Tourism and Cultural Change, 13, 191-207.

Bailey, A. W., \& Russell, K. C. (2010). Predictors of interpersonal growth in volunteer tourism: A latent curve approach. Leisure Sciences, 32(4), 352-368.

Boissevain, J. (1979). Tourism and the European periphery: The case of the Mediterranean. In D. Seers, B. Schaffer, \& M. Kiljunen (Eds.), Underdeveloped Europe: Studies in core periphery relations (pp. 125-135). London, England: Harvester Press.

Boukas, N. (2013). Towards understanding youth travel experiences in cultural heritage destinations: An integrated framework of youth cultural tourists' behaviour. International Journal of Tourism Anthropology, 3(1), 3-27.

Bramwell, B., \& Lane, B. (2014). The “critical turn” and its implications for sustainable tourism research. Journal of Sustainable Tourism, 22(1), 1-8.

Brown, N. (1992). Beachboys as culture brokers in Bakau Town, The Gambia. Community Development Journal, 27(4), 361-370.

Brunt, P., \& Courtney, P. (1999). Host perceptions of sociocultural impacts. Annals of Tourism Research, 2(3), 493-515.

Buzinde, C. N., \& Manuel-Navarrete, D. (2013). The social production of space in tourism enclaves: Mayan children's perceptions of tourism boundaries. Annals of Tourism Research, 43, 482-505.

Cammarota, J., \& Fine, M. (2008). Youth participatory action research: A pedagogy for transformational resistance. In J. Cammarota \& M. Fine (Eds.), Revolutionizing education: Youth participatory action research in motion (pp. 1-11). New York, NY: Routledge.

Canosa, A. (2014). The role of travel and mobility in processes of identity formation among the Positanesi. Tourist Studies: An International Journal, 14(2), 182-202.

Canosa, A., Brown, G., \& Bassan, H. (2001). Examining social relations between adolescent residents and tourists in an Italian coastal resort. Journal of Tourism Studies, 12(1), 50-59.

Canosa, A., \& Wray, M. (2013). The ‘voiceless’ population: Understanding the social impacts of tourism and their influence on the development of young people in tourist destinations. In M. Alvarez, E. Wickens, \& A. Bakir (Eds.), Sustainability Issues and Challenges in Tourism International Conference (pp. 53-57). Istanbul, Turkey: Bogazici University.

Chen, J. S. (2000). An investigation of urban residents' loyalty to tourism. Journal of Hospitality \& Tourism Research, 24(1), 5-19.

Cohen, E. (1982). Marginal paradises: Bungalow tourism on the islands of Southern Thailand. Annals of Tourism Research, 9(2), 189-228.

Crick, M. (1989). The hippy in Sri Lanka: A symbolic analysis of the imagery of school children in Kandy. Criticism, Heresy and Interpretation, 3, 37-54. 
Dahles, H., \& Bras, K. (1999). Entrepreneurs in romance: Tourism in Indonesia. Annals of Tourism Research, 26(2), 267-293.

Deery, M., Jago, L., \& Fredline, L. (2012). Rethinking social impacts of tourism research: A new research agenda. Tourism Management, 33(1), 64-73.

Easterling, D. S. (2004). The residents' perspective in tourism research. Journal of Travel and Tourism Marketing, 17(4), 45-62.

Faccioli, M. (2011). Youth's perception of tourism impact: Policy implications for Folgaria (Italy). International Journal of Tourism Policy, 4(1), 1-35.

Freire, P. (2000). Pedagogy of the oppressed (30th anniversary ed.). New York, NY: Bloomsbury. (Original work published 1970)

Gamradt, J. (1995). Jamaican children's representations of tourism. Annals of Tourism Research, 22(4), 735-762.

Gössling, S., Schumacher, K., Morelle, M., Berger, R., \& Heck, N. (2004). Tourism and street children in Antananarivo, Madagascar. Tourism and Hospitality Research, 5(2), 131-149.

Graburn, N. H. H. (1983). Editorial comments. Annals of Tourism Research, 10(1), 1-3.

Graham, A., Powell, M. A., Taylor, N., Anderson, D. L., \& Fitzgerald, R. M. (2013). Ethical research involving children. Florence, Italy: UNICEF Office of Research-Innocenti.

Gu, H., \& Ryan, C. (2008). Place attachment, identity and community impacts of tourism-The case of a Beijing hutong. Tourism Management, 29(4), 637-647.

Haralambopoulos, N., \& Pizam, A. (1996). Perceived impacts of tourism: The case of Samos. Annals of Tourism Research, 23(3), 503-526.

Higgins-Desbiolles, F., \& Whyte, K. P. (2013). No high hope for hopeful tourism: A critical comment. Annals of Tourism Research, 40, 428-433.

Hollinshead, K. (2009). The "worldmaking” prodigy of tourism: The reach and power of tourism in the dynamics of change and transformation. Tourism Analysis, 14(1), 139-152.

Hollinshead, K. (2010). Tourism studies and confined understanding: The call for a "new sense" postdisciplinary imaginary. Tourism Analysis, 15(4), 499-512.

Huberman, J. (2005). 'Consuming children': Reading the impacts of tourism in the city of Banaras. Childhood, 12(2), 161-176.

Huh, C., \& Vogt, C. A. (2008). Changes in residents' attitudes toward tourism over time: A cohort analytical approach. Journal of Travel Research, 46(4), 446-455.

Humes, W., \& Bryce, T. (2003). Post-structuralism and policy research in education. Journal of Education Policy, 18(2), 175-187.

Jafari, J. (2003). Research and scholarship: The basis of tourism education. Journal of Tourism Studies, 14(1), 6-16.

Jamal, T., Taillon, J., \& Dredge, D. (2011). Sustainable tourism pedagogy and academic-community collaboration: A progressive service-learning approach. Tourism and Hospitality Research, 11(2), 133-147.
Kincheloe, J. L., McLaren, P., \& Steinberg, S. R. (2011). Critical pedagody, and qualitative research: Moving to the bricolage. In N. K. Denzin \& Y. S. Lincoln (Eds.), The Sage handbook of qualitative research (pp. 163178). Los Angeles, CA: Sage.

Lanfant, M.-F., Allcock, J. B., \& Bruner, E. M. (Eds.). (1995). International tourism: Identity and change. London, England: Sage.

Leiper, N. (2004). Tourism management. Melbourne, Victoria, Australia: RMITT Press.

Leite, N., \& Graburn, N. (2009). Anthropological interventions in tourism studies. In T. Jamal \& M. Robinson (Eds.), The Sage handbook of tourism studies (pp. 35-64). Los Angeles, CA: Sage.

Long, P. H., \& Kayat, K. (2011). Residents’ perceptions of tourism impact and their support for tourism development: The case study of Cuc Phuong National Park, Ninh Binh Province, Vietnam. European Journal of Tourism Research, 4(2), 123-146.

Mathieson, A., \& Wall, G. (1982). Tourism: Economic, physical and social impacts. Essex, England: Longman Group.

Möller, P. (2012). Young adult transition in a tourism dominated rural area. Tourism Planning and Development, 9(4), 429-440.

Morrow, V. (2011). Understanding children and childhood (Centre for Children and Young People Background Briefing Series, No. 1, 2nd ed.). Lismore, New South Wales, Australia: Southern Cross University, Centre for Children and Young People.

Moyle, B. D., Croy, G., \& Weiler, B. (2010a). Community perceptions of tourism: Bruny and Magnetic Islands, Australia. Asia Pacific Journal of Tourism Research, 15(3), 353-366.

Moyle, B. D., Croy, G., \& Weiler, B. (2010b). Tourism interaction on islands: The community and visitor social exchange. International Journal of Culture, Tourism and Hospitality Research, 4(2), 96-107.

Moyle, B. D., Weiler, B., \& Croy, W. G. (2013). Visitors' perceptions of tourism impacts on Bruny and Magnetic Islands, Australia. Journal of Travel Research, 52(3), 392-406.

Murphy, P. E. (1985). Tourism: A community approach. London, England: Routledge.

Nash, D. (1989). Tourism as a form of imperialism. In V. L. Smith (Ed.), Hosts and guests: The anthropology of tourism (pp. 33-48). Philadelphia: University of Pennsylvania Press.

Nielsen, N., \& Wilson, E. (2012). From invisible to Indigenous-driven: A critical typology of research in Indigenous tourism. Journal of Hospitality and Tourism Management, 19, 1-9.

Nunkoo, R., \& Ramkissoon, H. (2010). Small island urban tourism: A residents' perspective. Current Issues in Tourism, 13(1), 37-60.

Nunkoo, R., Smith, S. L. J., \& Ramkissoon, H. (2013). Residents' attitudes to tourism: A longitudinal study of 140 articles from 1984 to 2010. Journal of Sustainable Tourism, 21(1), 5-25. 
Ortner, S. B. (1984). Theory in anthropology since the sixties. Comparative Studies in Society and History, 26(1), 126-166.

Poria, Y., \& Timothy, D. J. (2014). Where are the children in tourism research? Annals of Tourism Research, 47, 93-95.

Pritchard, A., Morgan, N., \& Ateljevic, I. (2011). Hopeful tourism: A new transformative perspective. Annals of Tourism Research, 38(3), 941-963.

Prout, A., \& James, A. (1997). A new paradigm for the sociology of chilhood? Provenance, promise and problems. In A. James \& A. Prout (Eds.), Constructing and reconstructing childhood: Contemporary issues in the sociological study of childhood (pp. 7-32). London, England: Taylor \& Francis.

Schänzel, H., Yeoman, I., \& Backer, E. (2012). Family tourism: Multidisciplinary perspectives. Bristol, England: Channel View.

Sharpley, R. (2014). Host perceptions of tourism: A review of the research. Tourism Management, 42, 37-49.

Small, J. (2008). The absence of childhood in tourism studies. Annals of Tourism Research, 35(3), 772-789.

Smith, A. B., \& Bjerke, H. (2009). Children's citizenship. In N. J. Taylor \& A. B. Smith (Eds.), Children as citizens? International voices (pp. 15-34). Dunedin, New Zealand: Otago University Press.

Smith, V. L. (Ed.). (1977). Hosts and guests: The anthropology of tourism. Philadelphia: University of Pennsylvania Press.

Swain, M. B. (1977). Gender roles in Indigenous tourism: Kuna Mola, Kuna Yala, and cultural survival. In V. L. Smith (Ed.), Hosts and guests: The anthropology of tourism. Philadelphia: University of Pennsylvania Press.

Thornton, P. R., Shaw, G., \& Williams, A. M. (1997). Tourist group holiday decision-making and behaviour:
The influence of children. Tourism Management, 18(5), 287-297.

Tovar, C., \& Lockwood, M. (2008). Social impacts of tourism: An Australian regional case study. International Journal of Tourism Research, 10(4), 365-378.

Tribe, J., Xiao, H., \& Chambers, D. (2012). The reflexive journal: Inside the black box. Annals of Tourism Research, 39(1), 7-35.

Walters, J., \& Davis, P. H. (2011). Human trafficking, sex tourism, and child exploitation on the Southern Border. Journal of Applied Research on Children: Informing Policy for Children at Risk, 2(1), 6.

Westwood, S. (2007). What lies beneath? Using creative, projective and participatory techniques in qualitative tourism inquiry. In I. Ateljevic, A. Pritchard, \& N. Morgan (Eds.), The critical turn in tourism studies: Innovative research methodologies (pp. 293-316). Oxford, England: Elsevier.

Wetherall, M., Taylor, S., \& Yates, S. J. (2001). Discourse theory and practice: A reader. London, England: Sage.

Witt, S. F. (1991). Tourism in Cyprus: Balancing the benefits and costs. Tourism Management, 12, 37-45.

Wood, R. E. (1980). International tourism and cultural change in Southeast Asia. Economic Development \& Cultural Change, 28(3), 561-581.

Wray, M. (2011). Adopting and implementing a transactive approach to sustainable tourism planning: Translating theory into practice. Journal of Sustainable Tourism, 19(4-5), 605-627.

Wu, M.-Y., \& Pearce, P. (2013). Looking down, looking out and looking forward: Tibetan youth view tourism in the future. In O. Mouffakir \& Y. Reisinger (Eds.), The host gaze in global tourism (pp. 125-142). Wallingford, England: CABI Publishing. 